\title{
THORACOSCOPIC LOOP LIGATION OF PARENCHYMAL BLEBS AND BULLAE: IS IT EFFECTIVE AND SAFE?
}

Hui-Ping Liu, MD

Chau-Hsiung Chang, MD

Pyng Jing Lin, MD

Ming-Jang Hsieh, MD
Surgeons who have gained experience and confidence with video-assisted thoracic surgery are now routinely applying the minimally invasive approach to treat patients with spontaneous pneumothorax. Although the endoscopic stapling device may be a preferred method for resection of parenchymal blebs or bullae, the stapling device is not inexpensive. In an effort to contain costs since we started performing the video-assisted thoracoscopic procedure in chest surgical diseases, we have used a selfmade endoscopic loop as an alternative method. It has assisted us in performing bulla ablation in a cost-effective manner. Over a 4-year period (1992 to 1996), we assessed the efficacy of ligating parenchymal blebs and bullae with a self-made endoscopic loop by video-assisted techniques. A total of 263 ligations were performed in 250 patients. Surgical indications included recurrence $(n=146)$, bilaterality of the disease $(n=13)$, hemopneumothorax $(n=7)$, radiologically demonstrated large bulla $(n=$ 9), persistent air leak $(n=52)$, and nonexpansion of the lung $(n=23$ ). There were no operative deaths. Early postoperative complications included a dislodged endoscopic loop necessitating reexploration in one patient and postoperative minor wound infections in 13 . The average postoperative hospitalization was 4.5 days. Two hundred seventeen patients (86.8\% of all patients) were followed up for a median of 28 months ( 1 to 46 months) after the operation. There have been no recurrences to date. Our results showed that thoracoscopic loop ligation is safe and effective in managing blebs and parenchymal bullae, with a lower cost, fewer complications, and a lower recurrence rate than provided by standard surgical techniques. On the basis of our results, we advocate the use of the self-made endoscopic loop for ligation of parenchymal blebs and bulla in patients with spontaneous pneumothorax to achieve a truly cost-effective and minimally invasive thoracoscopic procedure. (J Thorac Cardiovasc Surg 1997;113:50-4) pontaneous pneumothorax in apparently healthy $\checkmark$ individuals is relatively common, particularly in persons in their second or third decade of life. The objectives of treatment are to fully expand the affected lung, to control the complications, and to prevent recurrences. Standard surgical intervention

From the Department of Thoracic and Cardiovascular Surgery, Chang Gung Memorial Hospital, Chang Gung Medical College, Taipei, Taiwan, Republic of China.

Received for publication Feb. 9, 1996; revisions requested April 8, 1996; revisions received May 13, 1996; accepted for publication June 4, 1996.

Address for reprints: Hui-Ping Liu, MD, Thoracic and Cardiovascular Surgery, Chang Gung Memorial Hospital, 199, TunHwa North Rd., Taipei, Taiwan, Republic of China.

Copyright (C) 1997 by Mosby-Year Book, Inc.

$0022-5223 / 97 \$ 5.00+0 \quad \mathbf{1 2} / \mathbf{1} / \mathbf{7 5 5 2 1}$ has been by axillary or lateral thoracotomy through which bulla ablation or pleurodesis is performed. With advances in endoscopic surgery and instrumentation, this surgical approach has progressed to video-assisted thoracoscopic bullectomy with the use of an endoscopic stapling device (Endo-GIA stapler; Auto Suture Company Division, United States Surgical Corporation, Norwalk, Conn.). Since 1992, in an effort to contain costs, we have used thoracoscopic endoscopic loop ligation to ablate blebs or bullae. The results are equivalent to those achieved with an endoscopic stapling device. To assess the contribution of self-made endoscopic loop ligation in the management of parenchymal blebs or bullae, we describe our experience with this thoracoscopic approach in 250 patients with spontaneous pneumothorax. 

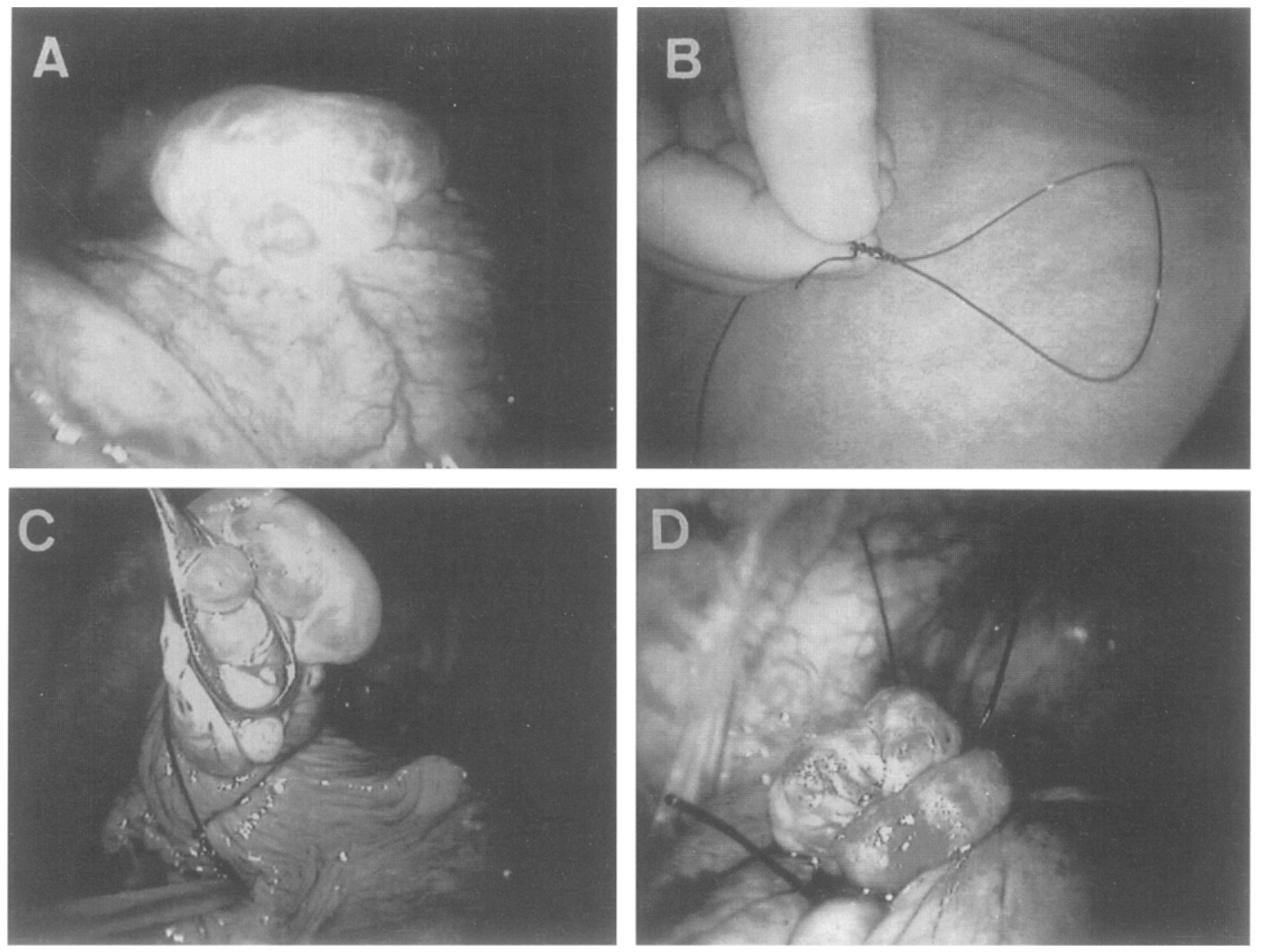

Fig. 1. A, Bulla identified at thoracoscopy. B, Extracorporeally created slipping loop. C, The slipping loop negotiated around the bulla beneath the ring forceps, which was then locked tightly in place with the push rod. D, At least two or three "self-made" loops were applied to prevent dislodgment of the ligature on lung expansion.

\section{Patients and methods}

During the 4-year period from 1992 to 1996,250 patients had a total of 263 endoscopic loop ligations for parenchymal blebs or bullae related to spontaneous pneumothorax. Two hundred thirty-seven patients underwent unilateral endoscopic loop ligations and 13, bilateral. Excluded from this study were 27 patients treated by thoracoscopic stapled resection before the development of endoscopic loop ligation for bullae. The age distribution ranged from 13 to 102 years, with the majority (76\%) of patients between 17 and 45 years old. One hundred seventy-two ligations were done on male patients and 91 on female patients, a 2:1 ratio. Forty-six patients (18.4\%) had known chest disease, $14(5.6 \%)$ had obstructive lung disease or asthma, and $38(15.2 \%)$ had old tuberculosis; no patient in this group had active tuberculosis at the time of the operation.

Surgical indications. Ligations were performed on 98 patients during the course of the first episode. Bilaterality was the indication in 13 patients, one of whom had simultaneous bilateral pneumothoraces. Fifty-two patients had the operation because of persistent air leak (beyond 10 days) and 23 because the lung failed to reexpand despite adequate tube suction drainage. Other indications included spontaneous hemopneumothorax (7 patients) and a large bulla seen on a roentgenogram ( 9 patients).

One hundred forty-six ligations were carried out because of recurrence. Most of these patients were not seen at the time of the first episode but were referred for elective bullectomy.

Operative technique. Patients were anesthetized and their lungs ventilated with either a double-lumen endotracheal tube or a bronchus blocker to allow one-lung ventilation and collapse of the ipsilateral lung. The patient was then placed in the lateral decubitus position as for a posterolateral thoracotomy. The initial trocar was placed in the fifth intercostal space in the midaxillary line, and an anterior incision $(2 \mathrm{~cm})$ was made in the third intercostal space in the anterior axillary line for a grasping instrument. The previously created chest tube hole was used for insertion of the endoscopic loop and for manipulation. The scope was introduced into the thoracic cavity through a trocar and the entire thoracic cavity was carefully examined with particular attention to the apex of the upper lobe of the lung. Introduction of a grasping forceps through the other incision aided in manipulation and exploration of the thoracic cavity. After the bulla was identified (Fig. 1,A), the externally or extracorporeally 
Table I. Modified Medical Research Council dyspnea scale

\begin{tabular}{|c|c|}
\hline Grade & Description \\
\hline 0 & $\begin{array}{l}\text { Not troubled with breathlessness except with strenuous } \\
\text { exercise }\end{array}$ \\
\hline 1 & $\begin{array}{l}\text { Troubled by shortness of breath when hurrying on a } \\
\text { level surface or walking up a slight hill }\end{array}$ \\
\hline 2 & $\begin{array}{l}\text { Walks slower than persons of the same age on a level } \\
\text { surface because of breathlessness or has to stop for } \\
\text { breath when walking at own pace on a level surface }\end{array}$ \\
\hline 3 & $\begin{array}{l}\text { Stops for breath after walking about } 100 \text { yards or after } \\
\text { a few minutes on a level surface }\end{array}$ \\
\hline 4 & $\begin{array}{l}\text { Too breathless to leave the house or breathless when } \\
\text { dressing or undressing }\end{array}$ \\
\hline
\end{tabular}

created slipping loop (Fig. 1, B) was inserted through one of the incisions. A ring forcep was then passed through the slipping endoscopic loop to grasp the bulla beyond the ligature. The slipping loop was negotiated around the bulla beneath the ring forceps (Fig. 1, C) and then locked tightly in place with the push rod. For each of the blebs or bullae, at least two to three self-made endoscopic loop of No. 1 polydioxanone suture (Ethicon, Inc., Somerville, N.J.) were applied to prevent dislodgment of the ligature on lung expansion (Fig. 1,D). The lung was then inflated and tested under water to assure that bullae and air leaks were completely ablated. After ligation of all visible blebs or bullae, pleural abrasion with sterilized mesh was performed over the entire apical surface of the parietal pleura. At the end of the procedure a No. 32 chest tube was inserted through one of the incision wounds to drain the pleural space. Prophylactic antibiotics were used in all patients. Postoperative data including duration of chest tube placement, hospital stay, and complications were all recorded.

\section{Results}

A total of 263 endoscopic loop ligations were successfully performed to ablate bullae through video-assisted thoracoscopy. A slight predilection for the right lung $(57 \%)$ over the left lung ( $43 \%$ ) was noted. The average size of the blebs or bullae identified at thoracoscopy was $2.5 \mathrm{~cm}$ (range 0.3 to 9 $\mathrm{cm}$ ). Blebs or bullae were positively identified in 211 patients $(84.4 \%)$. The sites of the bullous lesions were as follows: apex or confined to upper lobe only, 143; middle lobe, 11; lower lobe, 26; and multiple sites, 31. In 39 patients $(15.6 \%)$, thoracoscopic exploration did not disclose any bullae. However, we did see abnormal parenchymal changes with aberrant vascularization as well as fibrotic scarring of the apex, which may have contained underlying invisible subpleural vesicles. This may also have been the region in which a bulla had ruptured before and thus be the area for likely recurrence. In such circumstances, loop ligation was also applied to prevent such recurrence. An obvious perforation with an active air leak was noted in 37 patients $(14.8 \%)$. Of the total group, only one patient required a second operation for an air leak when an endoscopic loop (only one catgut loop ligature had been used) slipped from the lung parenchyma after a forceful sneeze 2 days after the operation. The air leak resolved 3 days after a second operation, done by a conventional suturing technique. No operative deaths were related to the procedure.

Thirteen patients had minor wound infections (previous chest tube site) that may have been due to previously prolonged chest tube placement. The median operating time was 40 minutes ( 25 to 70 minutes). The thoracic drains were removed after a median of 3.5 days (range 1 to 7 days) and the median postoperative stay was 4.5 days ( 2 to 14 days). Postoperatively, all patients obtained complete lung expansion, but nine patients had residual minimal apical pneumothorax after removal of the chest tube, which was treated conservatively. Twentysix patients complained of paresthesias over the chest wall in the dermatomal distribution of the fifth intercostal nerve 12 months after the operation. At subsequent follow-up, the majority of patients were free of symptoms, with only 11 patients noting wound discomfort related to weather changes. Two hundred seventeen patients ( $86.8 \%$ of all patients) were followed up for a median of 28 months ( 1 to 46 months) after the operation. There have been no recurrences to date. In patients with multiple bullae, subjective improvement in clinical symptoms after bulla ligation has been significant (grade 2 to grade 1) according to the Modified Medical Research Council dypnea scale (Table I). However, this improvement has not been consistently correlated with similar improvement in results of pulmonary function studies, mainly because most of the patients did not have preoperative pulmonary function studies.

\section{Discussion}

Although spontaneous pneumothorax can be related to a wide variety of intrathoracic diseases, most reported series recognize a young, "apparently healthy" group of patients and an older group with obstructive lung disease. The young patients are usually tall, thin, and male, ${ }^{1,2}$ and the condition almost invariably consists of small, apical, subpleural vesicles $^{3}$; sometimes, a scarred apex is the only recognizable lesion. ${ }^{3}$ In the older group, diffuse emphysematous changes with bulla formation are the rule. The methods of treatment should take into 
account these characteristics of the underlying lung disease. Closed tube thoracostomy is considered the main therapeutic approach in the majority of patients, but this method is usually ineffective in preventing recurrences. ${ }^{4}$ The other nonoperative therapies, including chemical pleurodesis with sclerosing agents, have frequently been associated with undesirable side effects and a low success rate. ${ }^{5}$ In light of these findings, the only effective therapy in preventing recurrences is surgical resection of the lung lesions.

Standard surgical intervention has been by axillary or lateral thoracotomy through which bleb or bulla ablation or pleurodesis is performed. In recent years, with the development of video-assisted thoracic surgery, thoracoscopic management of chest diseases as well as bullectomy has been a routine approach in our hospital. ${ }^{6-12}$ Thoracoscopy has become an accepted alternative approach in the management of chest diseases, as well as spontaneous pneumothorax. ${ }^{13-18}$ Video-assisted thoracic surgery allows inspection of the entire lung, identification and resection of bullous lesions, and mechanical pleurodesis, essentially duplicating an open procedure. Various surgical techniques have been used for bulla ablation. ${ }^{16-22}$ These include conventional suturing technique, electrocautery ablation, endoscopic stapling (Endo-GIA stapler), and neodymiun-yttrium-aluminum-garnet laser ablation of bleb or bulla by means of thoracoscopy. The optimal development of the endoscopic equipment for diagnostic and therapeutic purposes provides us with a start in the field of minimally invasive thoracic surgery, and the newly developed endoscopic stapler, cutter (Endo-GIA cutter), and laser beams have enabled us to replace some of the earlier operations necessitating classic thoracotomy with therapeutic thoracoscopy. However, the instruments and video equipment used for these procedures are not inexpensive. In comparing the total costs incurred by patients having undergone video-assisted thoracoscopic bulla ablation with those incurred by similar patients having had an open technique, we found that patients who underwent thoracoscopy were likely to spend more money in endoscopic disposable instruments. For most procedures performed thoracoscopically, the procedure cost is greatly increased by the instruments selected at the time of the operation. In general, the fewer endoscopic instruments used, the lower the overall cost.

In patients with bullous lung disease, a thoracoscopic approach has now been well established as a truly minimally invasive procedure associated with a shortened hospital stay. ${ }^{17,19}$ In comparison with our early experience, ${ }^{6,7,9}$ using the Endo-GIA stapler for bulla resection with later bulla ligation with a self-made endoscopic loop, we have seen a trend toward shorter operating room times and lower procedure charges. Until now, few reports have suggested using endoscopic loop ligation for bulla ablation in patients with spontaneous pneumotho$\operatorname{rax}^{21,22}$ and the benefits of the technique have not been fully investigated. The technique is more limited than the endoscopic stapling devices. In view of technical considerations, Akio Wakabayashi ${ }^{23}$ reported the use of electrocautery through a thoracoscope in treating spontaneous pneumothorax. Electrocautery was effective in sealing rupture blebs but failed to control air leaks from ruptured large bullae. LoCicero and associates ${ }^{24}$ reported using the carbon dioxide laser to seal an air leak but with only limited success. Hazelrigg and associates ${ }^{19}$ reported the use of the endoscopic stapling device for bulla ablation, but the device increased the operating cost. We question the popularity and cost-effectiveness of these thoracoscopic techniques that involve newly developed, expensive instruments in treating primary spontaneous pneumothorax. From our experience, endoscopic loop ligation of the bullae or blebs is simple and equal to endoscopic stapling devices or laser beams in effectiveness. An endoscopic stapling device is expensive, and usually several cartridges are needed for bulla resection. The cost for each set of Endo-GIA staplers is equivalent to $\$ 400$ (U.S. currency) in our country. Each bulla resection costs about the same or more, increasing charges. A self-made endoscopic loop costs only $\$ 12$ (U.S. currency) and can be effectively applied three times at each procedure.

We have obtained similar postoperative benefits using endoscopic loop ligation as with other techniques that use thoracoscopy in treating patients with primary spontaneous pneumothorax, ${ }^{6,9,17,19}$ with a similar short postoperative stay (4.5 days), less postoperative pain, and absence of recurrence of pneumothorax at a median follow-up of 28 months. A ligature became dislodged in only one patient, after a forceful sneeze 2 days after the operation. This occurred in one of the first three patients when we were using a commercial endoscopic loop (chromic catgut) for bulla ligation. After that, we changed to a self-made loop of No. 1 polydiaxanone suture (PDS II, Ethicon, Inc., Somerville, N.J.) for bulla ligation without any subse- 
quent complications. Two to three ligatures should be applied on one single bulla to assure the complete ablation of the bulla. It is our impression that thoracoscopic loop ligation of the visceral pleura as well as the base of the bulla is at least as good as stapler resection in ablating air leaks, and often better, because the ligation and shrunken bulla is often left behind and undergoes fibrosis. We did not further resect the distal part of the ligated bulla, because leaving it in place probably lessens the risk of air leak on lung expansion. We agree that, in certain circumstances, there may be diagnostic advantages in resecting part of the bulla, but most of the time we did not. We resect only in cases in which we suspect that the underlying tissue (bulla) might be abnormal.

In our experience, thoracoscopic bulla ligation was much easier and simpler than stapler resection. In terms of health-care cost, this is a truly costeffective approach in managing bullous disease. On the basis of our results, we advocate the routine use of the self-made endoscopic loop for ablation of the parenchymal bleb and bulla in patients with spontaneous pneumothorax to achieve a minimally invasive and truly cost-effective thoracoscopic procedure.

\section{REFERENCES}

1. Lichter I, Gwynne JF. Spontaneous pneumothorax in young subjects. Thorax 1971;26:409-17.

2. Askew AR. Parietal pleurectomy for recurrent pneumothorax. Br J Surg 1976;63:203-5.

3. Abyholm F, Storen G, Geiran O. Spontaneous pneumothorax. Scand J Thorac Cardiovase Surg 1975;9:281-6.

4. Getz SB Jr, Beasley WE III. Spontaneous pneumothorax. Am J Surg 1983;145:823-7.

5. Atzssi K, Pilorget A, Lewarie F, Menu P, Bignon J. Thoracostomy tube pleurodesis by collagen instillation. Intensive Care Med 1986;12:335-6.

6. Liu HP, Lin PJ, Hsieh MJ, Chang JP, Chang CH. Thoracoscopic surgery as a routine procedure for spontaneous pneumothorax-result from 82 patients. Chest 1995;107:559-62.

7. Liu HP, Lin PJ, Chang CH, Chang JP. Video-assisted thoracic surgery: manipulation without trocar in 112 consecutive procedure. Chest 1993;104:1452-4.

8. Liu HP, Chang CH, Lin PJ, Chang JP. Video-assisted endoscopic esophagectomies with stapled intrathoracic esophagogastric anastomosis. World J Surg 1995;19:745-7.

9. Liu HP, Chang CH, Lin PJ, Hsieh HC, Chang JP, Hsieh MJ. Video-assisted thoracic surgery: the Chang Gung experience. J Thorac Cardiovasc Surg 1994;108:834-40.

10. Liu HP, Chang CH, Lin PJ, Hsieh HC, Chang JP, Hsieh MJ. Thoracoscopic management of effusive pericardial disease: indications and technique. Ann Thorac Surg 1994;58: 1695-7.

11. Liu HP, Lin PJ, Hsieh MJ, Chang JP, Chang CH. Application of thoracoscopy for lung metastases. Chest 1995;107:266-8.

12. Liu HP, Chang CH, Lin PJ, Chang JP, Hsieh MJ. Thoracoscopic-assisted lobectomy: preliminary experience and results. Chest 1995;107:853-5.

13. Daniel TM, Tribble CG, Rogers BM. Thoracoscopy and talc poudrage for pneumothoraces and effusion. Ann Thorac Surg 1990;50:186-9.

14. Mack MJ, Aronoff RJ, Acuff TE, Douthit MB, Bowman RT, Ryan WH. Present role of thoracoscopy in the diagnosis and treatment of diseases of the chest. Ann Thorac Surg 1992; 54:403-8.

15. Vanderschueren RG. The role of thoracoscopy in the evaluation and management of pneumothorax. Lung 1990; 168(Suppl):1122-5.

16. Torre M, Belloni P. Nd:YAG laser pleurodesis through thoracoscopy: new curative therapy in spontaneous pneumothorax. Ann Thorac Surg 1989;47:887-9.

17. Cole FH Jr, Cole FH, Khandekar A, et al. Video assisted thoracic surgery: primary therapy for spontaneous pneumothorax. Ann Thorac Surg 1995;60:931-5.

18. Brenner M, Kayeleh RA, Milne EN, et al. Thoracoscopic laser ablation of pulmonary bullae. J Thorac Cardiovasc Surg 1994;107:883-90.

19. Hazelrigg SR, Landreneau RJ, Mack M, et al. Thoracoscopic stapled resection for spontaneous pneumothorax. J Thorac Cardiovasc Surg 1993;105:389-93.

20. Inderbitzi R, Furrer M. The surgical treatment of spontaneous pneumothorax by video-thoracoscopy. Thorac Cardiovase Surg 1992;40:330-3.

21. Nathanson LK, Shimi SM, Wood RAB, et al. Videothoracoscopic ligation of bulla and pleurectomy for spontaneous pneumothorax. Ann Thorac Surg 1991;52:316-9.

22. Youmans CR Jr, Williams RD, McMinn MR, Derrick JR. Surgical management of spontaneous pneumothorax by bleb ligation and pleural dry sponge abrasion. Am J Surg 1970; 120:644-8.

23. Wakabayashi A. Thoracoscopic ablation of blebs in the treatment of recurrent or persistent spontaneous pneumothorax. Ann Thorac Surg 1989;48:651-3.

24. LoCicero J III, Hartz RS, Frederiksen JW, Michaelis LL. New applications of the laser in pulmonary surgery: hemostasis and sealing of air leaks. Ann Thorac Surg 1985;40:54650 . 